\title{
THE EFFECT OF ANKLE AND SUBTALAR JOINT SOMATIC DYSFUNCTION CORRECTION TO IMPROVE ORIENTEER STATIC BALANCE
}

\author{
Baiba Smila \\ Latvian Academy of Sport Education, Latvia \\ Andra Fernāte \\ Latvian Academy of Sport Education, Latvia \\ Velga Zaliaiskalna \\ Medical centre 8, Latvia
}

\begin{abstract}
The most frequent injuries among sports orienteers are the ankle injuries. The one of the most effective means to prevent the ankle injuries and recurrent ankle injuries is balance and stability development. The aim of this study is to find out the most effective method to develop static stability in the previously injured ankle for orienteers: osteopathic treatment of the ankle and subtalar joints or balance exercises, or the combination of osteopathic treatment of the ankle and subtalar joints and balance exercises. The effectiveness analysis of the intervention methods was conducted with the use of Digital Balance Analyzer (DBA) for the assessment of statical balance. 36 orienteers (12 to 18 years old) were randomized in three groups to an intervention, after being assessed at baseline and then reassessed one week later. Static balance improvements are only when using osteopathy and ankle joints subtalar somatic dysfunction correction together with balance exercises. Separate osteopathy or balance exercises will not give results as effective as the combination of these two effects.
\end{abstract}

Keywords: ankle and subtalar joint somatic dysfunction correction, orienteers`static balance improvement, osteopathy.

\section{Introduction}

The number of sports injuries is increasing (Tiirikainen et al., 2008). One of the most common injuries for orienteers is subtalar joint sprain: both primary and recurrent (Leumann, 2013; Fors, Winblad, 2015). As suggested by a research on 43 orienteers of the Swiss Orienteering National Team, 86\% were found to have an acute ankle sprain $(\mathrm{n}=37)$, seven athletes $(16 \%)$ were found to have suffered unilateral and 30 athletes $(70 \%)$ bilateral ankle sprains. Similar studies have been carried out with orienteers from Finland and other countries as well (Leumann et al., 2013). This proves that orienteering has a high risk level for such injuries. 
One of the most effective preventive measures for these injuries is balance training (Mattacola, Dwyer, 2002). Balance (also called proprioceptive) training does not prevent all injuries, but reduces ankle injuries. The proprioceptive/neuromuscular training reduces the incidence of certain types of sports injuries among adolescent and young adult athletes during pivoting sports (Hübscher et al., 2010). A neuromuscular training and injury prevention counselling programme is effective in preventing acute ankle and upperextremity injuries (Parkkari et al., 2011).

Therefore the aim of the study is to find out the most effective method to develop static stability in the previously injured ankle for orienteers: osteopathic treatment of the ankle and subtalar joints or balance exercises, or the combination of osteopathic treatment of the ankle and subtalar joints and balance exercises.

\section{Theoretical framework}

There are 26 bones in the foot. The ankle and subtalar joints have the most important role in foot biomechanics (Sobotta, 2004). Joints provide a functionally correct step while both walking and running. The function of the ankle joint is plantar flexion and dorsiflexion of the foot, while the function of the subtalar joint ensures inversion and eversion of the foot (Leardini et al., 2014). The majority of ankle eversion/inversion occurs at the subtalar joint; however, the ankle component cannot be ignored (Arndt et al., 2004). While walking and running, the ankle constantly adapts to terrain. The tarsal, metatarsal and phalanx bones act as primary stabilizers and adjust the foot to each support surface or our movement style. In turn, these small movements affect the stabilizing adaptation of the heel bone, the talus bone and the ankle joint, as the information is transmitted to the central balance analyzer in the medulla of the central nervous system (CNS). Thus the ankle plays an important role in maintaining balance both on the move and in static positions.

Balance is the ability to maintain a state in various movements and poses. Balance is provided by the balance centre in the CNS, where the information is received from the vestibular, visual, auditory and somatosensory analyzers. Proprioceptors have a key role in the somatosensory analyzer system. Vestibular nucleus neurons respond to the changes of the extremity state, body turns, signals from the internal organs, i.e. provide information synthesis, which comes from various sources. Various movement responses are controlled and managed at the same time. Peripheral proprioceptors are located in both muscles and joints. These receptors respond to mechanical irritation and participate in movement coordination. They serve as a source of information on the state in which the particular part of the body is located in space. In literature muscle 
proprioceptors have been studied more (Ward, 2003). Joint receptors respond to the position of the joint and the joint angle changes, thereby being a link in feedback for sending information through efferent pathways to the CNS.

The term ,somatic dysfunction” is a key concept of osteopathic medicine. In osteopathy it is assumed as an axiom that the body - bag and viscera - has the ability to self-heal, and this unique ability of the body is respected and revitalized with osteopathic manipulations. A thorough structural examination and testing is primarily essential in a patient's osteopathic examination in order to detect somatic and visceral dysfunctions (Ward, 2003). Physical processes, which activate in the somatic dysfunction zone, alter neural activity in the respective spinal segment (facilitation forms), as well as change the body's endocrine and immune response (Zemītis, 2003).

Articular techniques is one of the possible influence types - osteopathy has a whole arsenal of them, based on precise knowledge of the specific joint's anatomy and biomechanics, and a reinforced osteopathic „tissue sense" - hand sensitivity. Other possible technique types are trusts (Zemītis, 2003) - very rapid movements of small amplitude, fascial techniques, where the togetherness and continuity phenomenon of the connective tissue system in the human body is used, fluid techniques (Ward, 2003; Jealous, 2000), where correction of the somatic dysfunction is achieved with the help of the body's internal hydrodynamic potential, as well as energetic techniques, where in the classic medicine yet unrecognized energetic potential of a living being is effectively used.

The ankle and subtalar joints have an important functional role in ensuring balance of the body. Good balance guarantees coordinated and energy-saving movements, which are important to orienteers as representatives of an endurance sport, who run on uneven surfaces, reading a map at the same time. The most common injuries in this sport are an ankle sprain of the supination type. Typically, a once traumatized ankle may be repeatedly injured (Leumann et al., 2013; Fors, Winblad, 2015). As regards prevention of the repeated injuries, articles mainly have information on exercising for ankle strengthening, as well as passive stability ensuring measures - tape wrapping and wearing orthopaedic insoles (Leumann et al., 2013; Kujala et al., 1995). We were interested in the opportunity to find the most effective active stability regenerating tool, using an osteopathic method, and to assess how it can be combined with special balance exercises.

\section{Methodology of the research}

During the experiment 8 balance index measurements were made for 36 SP „Auseklis" orienteers aged from 12 to 18, of which, by osteopathic testing, 29 
were found to have an ankle and subtalar joint somatic dysfunction. On the first day of the orientation camp four measurements were made and four measurements were made on the last - seventh - day of the camp.

The Balance Index (BI) was determined with the subject taking a posture according to the Bondarevsky method. The subject stood on one leg, the hands on the hips, the other leg bent in the knee joint. The foot relaxed in the support leg's knee joint, looking forward. The balance was tested standing on both the right and left leg with the eyes open and with the eyes and ears closed. Testing on the Digital Balance Analyzer (DBA) platform with the ears and eyes closed was carried out in order to exclude as many senses as possible, which help to keep balance. By excluding eyesight and hearing, the neutralization of external influence impulses on the central vestibular analyzer was achieved. In turn, the internal sense of balance, which is provided by muscle and joint proprioception, is very important for orienteers in order not to injure themselves, while running through a forest and reading a map at the same time. For the neutralization of the auditory information, which also creates external influence impulses on the central vestibular apparatus in CNS, sport shooter's earphones were used, which are typically used in shooting-galleries in order to protect the hearing apparatus from loud noises. Thus, during the balance testing a complete sound isolation was achieved. A blindfold was used for eyesight exclusion.

Testing was carried out for 1 minute for both the right and the left leg in two variants: with the eyes and ears both open and closed. Static Force Platform measures the displacement of a subject's centre of pressure while standing still using three or four force transducers (Murray et al., 1975). Testing was carried out in a room with a DBA platform. The platform was connected to the computer program DBA-Ruler for data recording and analysis. The DBA platform was used to measure the BI (range from 0 "excellent balance" to 10 "very poor balance"). The DBA platform records balance fluctuations, according to which the BI is calculated. The less foot fluctuations have been recorded, the lower the balance index, and vice versa - the higher and the more fluctuations, the higher the balance index.

For this research after the first balance test on the DBA platform an osteopathic examination of both legs was carried out on all orienteers, checking the ankle and the subtalar joints and determining the existence of somatic dysfunctions. The found dysfunctions were corrected with an appropriate method - articular technique (Zemìtis, 2003). In other words - with the athlete lying on his/her back, one therapist's hand clasping the ankle from the top and the other - the foot from the bottom, joint surfaces are gradually slipped into opposite directions until a free movement in a normal amount is achieved in the sagittal plane. The articular technique of the subtalar joint is as follows: the athlete is lying on his/her back. One therapist's hand clasps the patient's heel 
from the bottom, another hand firmly encircles the talus bone from the top. Traction is carried out with both hands along the tibias axis and at the same time the upper arm moves the talus bone in inversion. The technique is carried out until a natural movement between the two bones is freed.

Initially the orienteers were divided into 3 groups:

Group 1 - orienteers, for which the ankle and foot somatic dysfunctions had not been found. These young people performed balance exercises on a regular basis for a whole week 2 times a day;

Group 2 - orienteers, for which the ankle and foot somatic dysfunctions had been found. For these young people the ankle state correction was performed in the ankle and subtalar joints with a corresponding articular osteopathic technique during the first 2 days of the camp;

Group 3 - orienteers, for which the ankle and foot somatic dysfunctions had been found. For these young people the ankle state correction was performed in the subtalar and ankle joints with a corresponding articular osteopathic technique during the first 2 days of the camp, as well as they performed balance exercises on a regular basis for a whole week 2 times a day.

For all groups the static balance for the right and left leg with the ears and eyes both closed and opened was determined on the first and last day of the camp. During the experiment at the same time with the three initial groups, group 4 and group 5 were performed:

Group 4 - in this group information was gathered on the balance changes for the healthy leg of Group 2 orienteers;

Group 5 - in this group information was gathered on the balance changes for the healthy leg of Group 3 orienteers.

For groups 1, 3 and 5 the following balance exercise set was created and modified (Peterson\&Renstrom, 2001; Cyriax, 1980; Reyneke, 2002; Siler, 2000):

Exercise 1. The starting position - standing, the legs together, the hands on the hips. Athlete rises on tiptoes, holds the position, maintaining stable ankles (trying to avoid foot inversion). The exercise is repeated 5 times.

Exercise 2. The starting position - standing on one leg, the hands on the hips. The other leg is stretched in front, holds a strong position for as long as possible, then this leg is stretched to the side, holds as long as possible, then to the back, holds as long as possible. During the exercise vertical body axis is to be maintained. The same with the other leg. The exercise is repeated 2 times.

Exercise 3. The starting position - standing on an Airex pillow, the feet are placed hip width apart. Squats until the knees bend at a straight angle and in the frontal plane places above the foot (biomechanically correctly executed squat). The exercise is repeated 10 times. 
Exercise 4. The starting position - standing on one leg, the other is pressed against the back of the support leg. To rise on one leg's tiptoes while maintaining ankle stability and to slowly, in a controlled manner descend back. The exercise is repeated 5 times.

Exercise 5. The starting position - standing on the left leg, the right one is bent in the knee. With the right hand an athlete slowly reaches towards the floor at the centre line and slowly rises to the starting position. Next time he/she reaches with the hand towards an imaginary point on the floor, which is to the left of the centre line. The third time he/she reaches with the hand towards an imaginary point, which is to the right of the centre line. The exercise is repeated 2 times.

Exercise 6. The starting position - standing next to the Airex pillow. An athlete squats and performs an energetic lateral jump with landing on one leg. The task is to remain stable on one leg after landing. The exercise is repeated 5 times.

Exercise 7. The starting position - standing on one leg on the Airex pillow, the hands on the hips, the eyes closed. The other leg is stretched in front, an athlete keeps a strong vertical position for as long as possible, then this leg is stretched to the side, holds for as long as possible, then this leg is stretched to the reward, holds for as long as possible, to maintain a vertical body axis as possible. The same with the other leg. The exercise is repeated 2 times.

The balance exercise set was created mainly to develop the deep muscles of the lower leg, as well as proprioception of the foot and the ankle, because in ensuring the balance the highest functional load is on the joints, which are close to the support surface. Soft support surfaces were used during the exercises in order to increase the load specifically for the ankle's stability and to imitate a natural soft, unstable surface, characteristic of orienteering run through forests, meadows and swamps.

SPSS Statistics (version 17.0) data processing programme was used for data analysis, where descriptive statistics was carried out. Kolmogorov-Smirnov criterion was used to determine whether the data are parametric or nonparametric. Non-parametric statistics correlation analysis method was used to determine Spearman's rank correlation coefficient, as well as Wilcoxson Signed Rank test was used.

\section{Results}

Looking at the overall balance index dynamics before and after the experiment with the eyes both closed and opened, it can be concluded that in all groups after the experiment, which lasted for a week, there is a tendency for the balance index to improve (see Figure 1). 


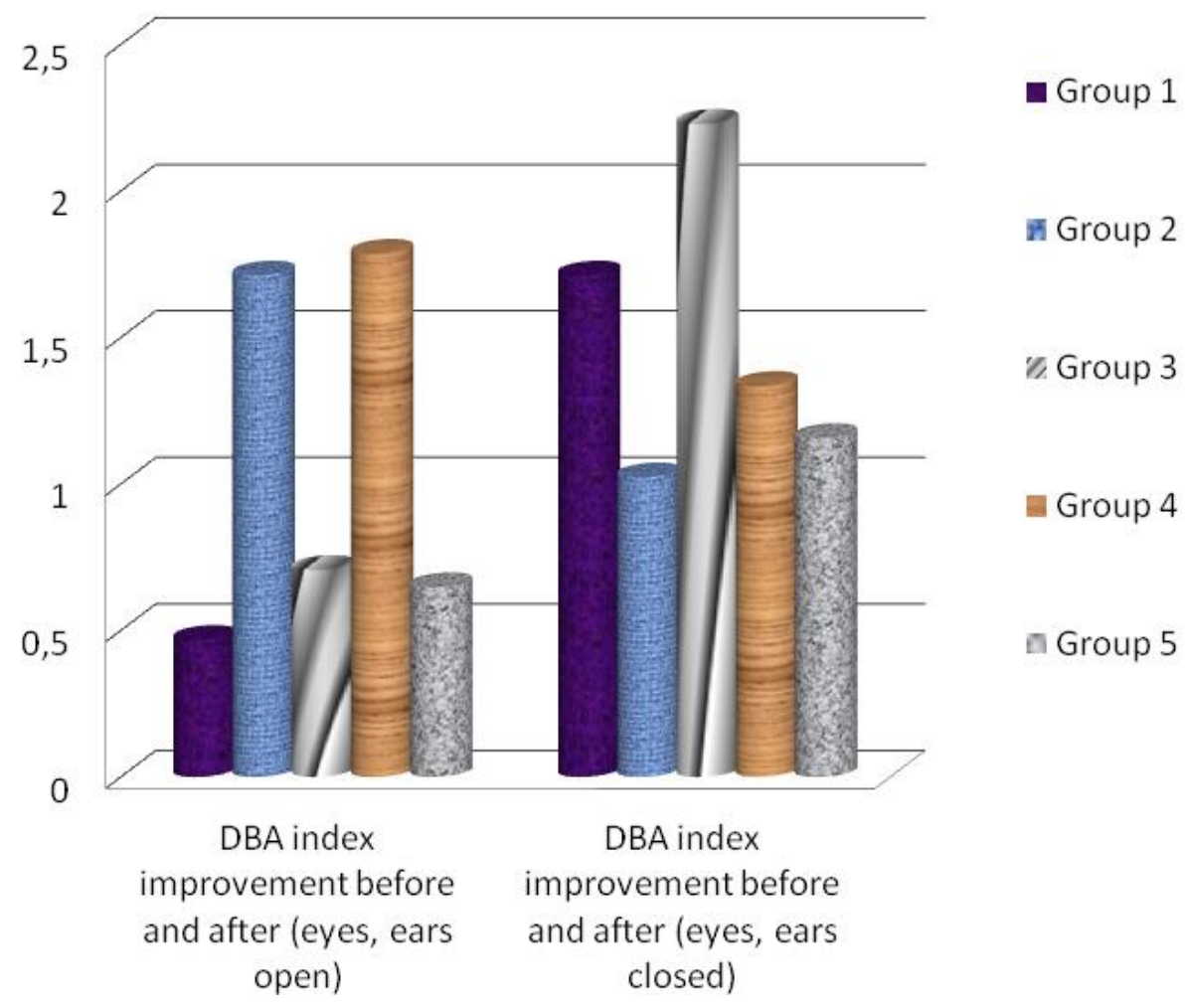

Figure 1 Decrease of Balance Index for the 5 experimental groups before and after the experiment

According to Figure 1 it can be observed that the highest increase of the static balance (excluding eyesight and hearing analyzers) was evident in Group 3 , for which both osteopathy and balance exercises were used together. For this group the balance test was carried out on the leg, on which the osteopathic correction was initially performed and then the exercise programme for balance training. The balance index has improved by 2.229 and this result is statistically significant $(p=0.026)$. Improvement of the rest of the balance indexes can be assessed only as a trend, because the result changes are not statistically significant. However, the overall conclusion is that after the experiment the greatest result improvements were observed in the tests, which were carried out with closed eyes and ears (excluding eyesight and hearing), so the main information "gateway" for the central body balance analyzer was proprioception. By contrast, when performing the static balance test with the ears and eyes opened, the greatest balance ability improvement was observed for the group, for which only the osteopathic method was used for the ankle's structural adjustment. Result improvement was observed for both the healthy leg and the previously traumatized leg with somatic dysfunctions, which were corrected. However, we once again want to point out that, since these results are 
Baiba Smila, Andra Fernāte, Velga Zaļaiskalna. The Effect of Ankle and Subtalar Joint Somatic Dysfunction Correction to Improve Orienteer Static Balance

not statistically significant, they can be judged only as a static balance improvement trend.

Observing the correlations between the static balance test's initial and postexperiment results of Group 3 (Fig. 2), it was determined that there is a strong correlation in the static balance test results before and after the experiment with closed eyes and ears $\left(\mathrm{r}_{\mathrm{s}}=.696, \mathrm{p}<0.01\right)$, as well as there is a strong correlation between performance results in the static balance test with ears and eyes opened before the experiment and the performance results in the static balance test with closed eyes and ears before the experiment $\left(\mathrm{r}_{\mathrm{s}}=.703, \mathrm{p}<0.01\right)$ and a strong correlation after the experiment $\left(\mathrm{r}_{\mathrm{s}}=.622, \mathrm{p}<0.05\right)$.

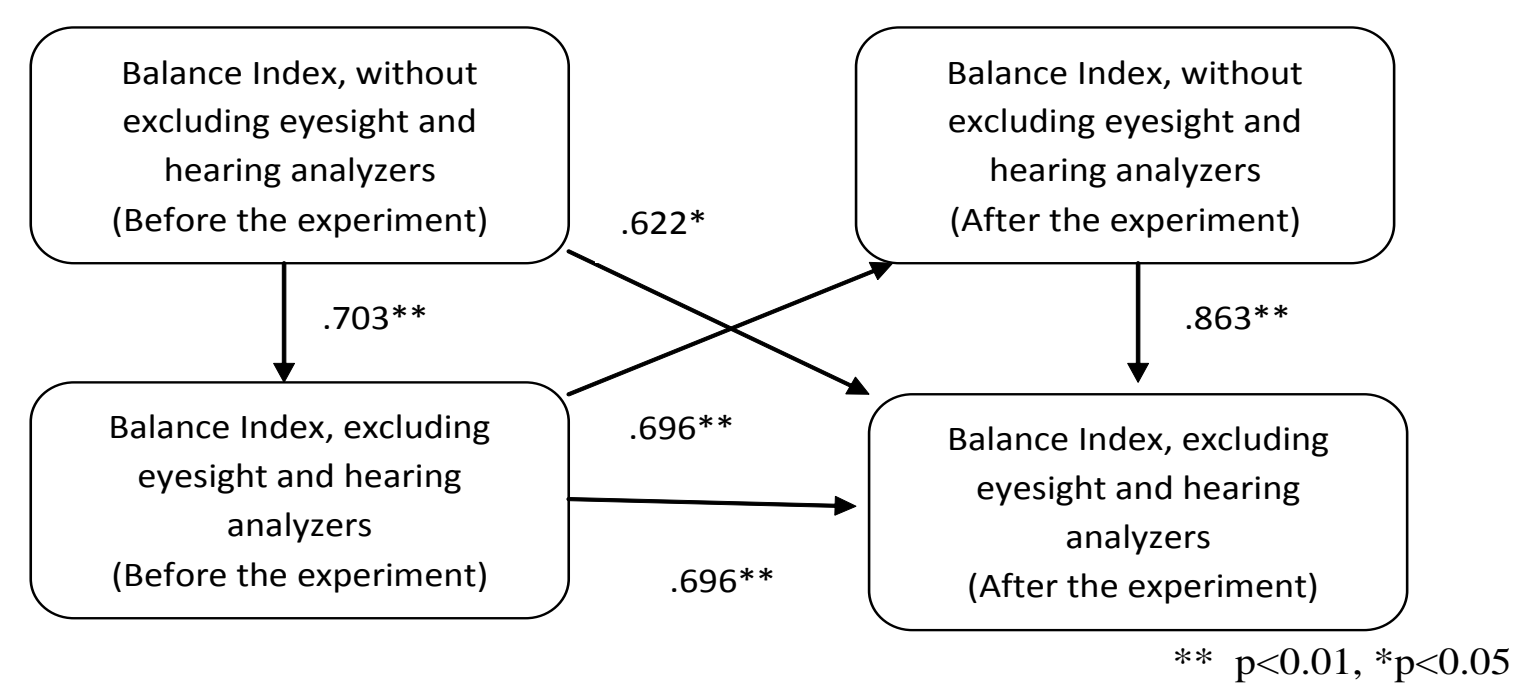

Figure 2 Correlation of the Static Balance Test results for Group 3 by Spearman $(n=16)$

There is a very strong correlation in the test results with ears and eyes opened and closed after the experiment $\left(\mathrm{r}_{\mathrm{s}}=.863, \mathrm{p}<0.01\right)$. Consequently, if orienteers of Group 3 before the experiment have a high balance index in the static balance test, excluding eyesight and hearing analyzers, then after the experiment, excluding eyesight and hearing analyzers, the balance index in the test will increase. The overall conclusion is that the only statistically significant result improvement changes are in Group 3 in the DBA static balance test with the ears and eyes closed. That is, the balance index improved by 2.229 units. Consequently, application of osteopathy and balance exercises is the most effective method for static stability improvement.

\section{Discussion}

In order to prevent chronic instability injuries, 35\% athletes of Swiss orienteering team trained their lower leg muscles weekly, specifically in a force- 
gymnastic programme for at least 10-20 minutes. 51\% athletes did this programme on an irregular basis and $12 \%$ athletes never (Leumann et al., 2013), but this programme does not include balance exercises.

Considerable improvements of static balance are achieved only by applying osteopathy for correction of the ankle and subtalar joint somatic dysfunction together with balance exercises. Performing osteopathy or a balance exercise set separately will not give as effective results as the combination of the two influences. In our opinion, it is these results that confirm the fact that by structurally adjusting the movement and support apparatus, it still will not bring the desired results for a full recovery of the function. An osteopath definitely should suggest orienteers an application of further physical load (corresponding exercises). However, after an ankle injuries (ligament strains, bone subluxations), which is a typical sports injuries in different sports, including sports orienteering in terrain, before applying a rehabilitation exercise programme there is a justified reason to perform correction of the foot and ankle somatic dysfunctions. Combined with subsequent balance and coordination exercises, it will restore the joint's stability and will be a guarantee for the prevention of future repeated traumas.

\section{Conclusions}

1. The combination of osteopathic treatment for the ankle and subtalar joints and balance exercises is the most effective method for developing static stability in the previously injured ankle for orienteers, the balance index improves by $2.23 \quad(\mathrm{p}=0.026)$, in comparison to separately applied osteopathy and balance exercise method.

2. The study showed that for the recovery of a wholesome function, i.e. balance, both components are necessary - both structural adjustment and the subsequent functional balance training.

\section{References}

Arndt, A., Westblad, P., Winson, I., Hashimoto, T., \& Lundberg, A. (2004). Ankle and Subtalar Kinematics Measured with Intracortical Pins During the Stance Phase of Walking. Foot Ankle Int., 25, N5, 357-64.

Cyriax, J. (1980). Textbook of Orthopaedic Medicine Volume 2: Treatment by Manipulation, Massage and Injection. UK: Harcourt publishers.

Fors, R.,\& Winblad, G. (2015). Skador bland elitorienterare - en beskrivande och jämförande studie. Uppsala Universitet. Retrieved from http://www.goranwinblad.se/wpcontent/uploads/2015/01/Skador-bland-elitorienterare-en-beskrivande-ochj\%C3\%A4mf\%C3\%B6rande-studie.pdf 
Baiba Smila, Andra Fernāte, Velga Zaļaiskalna. The Effect of Ankle and Subtalar Joint Somatic Dysfunction Correction to Improve Orienteer Static Balance

Hübscher, M., Zech, A., Pfeifer, K., Hänsel, F., Vogt, L., \& Banzer, W. (2010). Neuromuscular training for sports injury prevention: a systematic review. Medicine and Science in Sports and Exercise, 42(3), 413-421.

Jealous, J. (2000). The Fluid Body Overview, Biodynamics of Osteopathy. Audio CD Audiobook.

Kujala, U.M., Nylund, T., \& Taimela, S. (1995). Acute Injuries in Orienteerers. International Journal of Sports Medicine, 16, 122-125. https://www.thieme-connect.com/ products/ejournals/abstract/10.1055/s-2007-972977

Leardini, A., O’Connor J.J., \& Giannini S. (2014). Biomechanics of the Natural, Arthritic, and Replaced Human Ankle Joint. Journal of Foot and Ankle Research, 7, 8. http://jfootankleres.biomedcentral.com/articles/10.1186/1757-1146-7-8

Leumann, A. (2013). Injuries in Orienteering-Ankle Instability and Overuse Injuries. Scientific Journal of Orienteering, 18, 1, 24-28. http://orienteering.org/wpcontent/uploads/2010/12/Scientific-Journal-of-Orienteering-2013-Vol.18.pdf

Leumann, A., Zuest, P., Valderrabano, V., Clenin, G., Marti, B., \& Hintermann, B. (2013). Chronic Ankle Instability in the Swiss Orienteering National Team. Scientific Journal of Orienteering, 18, 12-23. http://orienteering.org/wp-content/uploads/2010/12/ Scientific-Journal-of-Orienteering-2013-Vol.18.pdf

Mattacola, C.G., \& Dwyer, M.K. (2002). Rehabilitation of the Ankle after Acute Sprain or Chronic Instability. Journal of Athletic Training, 37(4), 413-429.

Murray, M., Seireg, A., Sepic, S. (1975). Normal Postural Stability and Steadiness: Quantitative Assessment. The Journal of Bone and Joint Surgery, 57A, 510 - 516.

Parkkari, J., Taanila, H., Suni, J., Mattila, V.M., Ohrankämmen, O., Vuorinen P., Kannus, P., \& Pihlajamäki, H. (2011). Neuromuscular Training with Injury Prevention Counselling to Decrease the Risk of Acute Musculoskeletal Injury in Young Men during Military Service: a Population-based, randomised study. BMC Medicine. doi:10.1186/17417015-9-35 http://bmcmedicine.biomedcentral.com/articles/10.1186/1741-7015-9-35

Peterson, L., \& Renstrom, P. (2001). Sport injuries: Their Prevention and Treatment. UK: Martin Dunitz Ltd.

Reyneke, D. (2002). Ultimate Pilates Achieve the Perfect Body Shape. UK: Vermilion.

Siler, B. (2000).The Pilates Body. UK: Michael Joseph Ltd.

Sobotta, J. (2004). Atlas der anatomie des menchen. DE:Uraban \& fishcer.

Tiirikainen, K., Lounamaa, A., Paavola, M., Kumpula, H., \& Parkkari, J.(2008). Trend in Sports Injuries among Young People in Finland. International Journal of Sports Medicine, 29(6),529-536. https://www.thieme-connect.de/DOI/DOI?10.1055/s-2007965332

Ward, R. (2003). Foundations for osteopathic medicine. Second edition. US: American osteopatic association, Lippincott Williams \& Wilkins.

Zemītis, A. (2003). Strukturāla osteopātija. Mīksto audu tehnikas neiromuskularā masāža, artikulārās tehnikas. LU MPII OMS. 